\title{
Tratamento de sementes com rizobactérias na produção de cebola
}

\author{
Seed treatment with rhizobacteria the onion production
}

\author{
Oscar Emilio Ludtke Harthmann ${ }^{\mathrm{I}}$ Átila Francisco MógorII \\ João Américo Wordell Filho ${ }^{\text {III }}$ Wilmar Cório da Luz $^{\text {IV }}$ Luiz Antonio Biasi ${ }^{\text {II }}$
}

RESUMO

A associação de plantas com rizobactérias benéficas pode promover o crescimento vegetal e o biocontrole de doenças, reduzindo custos de produção e diminuindo o impacto dos agrotóxicos no meio ambiente. Com o objetivo de avaliar os efeitos de rizobactérias aplicadas às sementes de cebola 'Bola Precoce' no desenvolvimento de plantas e na produção de bulbos, foi conduzido um estudo na Estação Experimental da Epagri de Ituporanga, Santa Catarina, em 2007. Foram avaliadas as rizobactérias Pseudomonas spp. (W1, W2, W5, W6), Bacillus megaterium (W7, W19), Pseudomonas alcaligenes (W15), Paenibacillus polymyxa (W18), Bacillus cereus (UFV 040) e Pseudomonas putida (UFV 043), juntamente com uma testemunha não microbiolizada. Verificou-se que existe influência das rizobactérias testadas no desenvolvimento da cebola. Os isolados que apresentaram melhor rendimento de bulbos foram Pseudomonas spp. W6 e Bacillus cereus UFV40. Os aumentos de rendimento de bulbos em razão das rizobactérias variaram entre 3\% e 48\%. Essas bactérias promotoras de crescimento apresentam-se promissoras como bioinoculantes para serem utilizados na produção de cebola.

Palavras-chave: Allium cepa, RPCV, microbiolização.

\section{ABSTRACT}

Plant association with benefic rhizobacteria can enhance plant growth and diseases biocontrol, reducing production costs and environment pesticides impact. The experiment was carried out at the Experimental Station of the Epagri, Ituporanga, State of Santa Catarina, Brazil in 2007 to evaluate the effect of microbiolization with rhizobacteria on onion seed 'Bola Precoce' in plants development and bulb yield. The rhizobacteria Pseudomonas spp. (W1, W2, W5, W6), Bacillus megaterium (W7, W19), Pseudomonas alcaligenes (W15), Paenibacillus polymyxa (W18), Bacillus cereus (UFV 040), Pseudomonas putida (UFV 043), were used as inoculants and compared with non treated check. There was influence of rhizobacteria tested on the onion development. The treatment with Pseudomonas spp. (W6) and Bacillus cereus (UFV40) showed significantly increased bulb yield. Yield increases by the rhizobacteria varied from 3\% to $48 \%$. Rhizobacteria are promising as bioinoculant, for use in onion production.

Key words: Allium cepa, PGPR, microbiolization.

\section{INTRODUÇÃO}

Na rizosfera, região do solo que circunda a raiz e está sob a influência do sistema radicular, predominam bactérias de vida livre ou associadas aos tecidos das plantas. O termo rizobactéria caracteriza as bactérias da rizosfera que colonizam as raízes, denominadas rizobactérias promotoras de crescimento vegetal (RPCV) quando apresentam efeitos positivos sobre as culturas (LUZ, 1996). Vários gêneros bacterianos são conhecidos pela capacidade de promover o crescimento vegetal, dentre eles, Bacillus e Pseudomonas são de importância reconhecida e comercialmente utilizados como inoculantes e biofertilizantes em muitos países (KLOEPPER et al., 2004; BASHAN \& BASHAN, 2005).

Instituto Federal de Educação, Ciência e Tecnologia Catarinense. Estrada do Redentor, 5665, Bairro Canta Galo, CP 441, 89160000, Rio do Sul, SC, Brasil. E-mail: oscarelh@gmail.com. Autor para correspondência.

IICurso de Pós-graduação em Agronomia, Produção Vegetal, Universidade Federal do Paraná (UFPR), CP 19061, 81531-990, Curitiba, PR, Brasil.

IIIEmpresa de Pesquisa Agropecuária e Extensão Rural de Santa Catarina (EPAGRI - CEPAF), Chapecó, SC, Brasil.

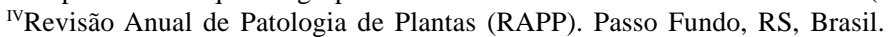


Uma vez que a sustentabilidade é uma direção a ser seguida na produção de alimentos, o uso de rizobactérias é considerado uma alternativa para a redução ou substituição do uso de produtos químicos sintéticos (CASTRO \& MELO, 2007; SHAHAROONA et al., 2008), seja diretamente como promotoras de crescimento, seja como agentes de controle biológico de doenças (FREITAS \& AGUILAR-VILDOSO, 2004).

As rizobactérias exercem efeito benéfico sobre as plantas por diferentes mecanismos de ação, diretos ou indiretos, como, por exemplo, a antibiose, o parasitismo, a competição, a produção de sideróforos e a indução de resistência (RAMAMOORTHY et al., 2001; TARNAWSKI et al., 2006). As rizobactérias são capazes de se multiplicar e colonizar rapidamente o sistema radicular, prevenindo a invasão de patógenos pela produção de metabólitos secundários que inibem outros microrganismos deletérios (KLOEPPER et al., 2004).

A microbiolização de rizobactérias em sementes de cebola pode promover respostas significativas. Os efeitos na promoção de crescimento incluem aumentos na altura, no número de folhas, na biomassa da parte aérea e da raiz, e na produção de bulbos. BADAWY et al. (2003) demonstraram que a inoculação de uma mistura de estirpes diazotróficas e um isolado solubilizador de fosfato promoveram o crescimento de raízes e folhas de cebola e aumentaram o rendimento de bulbos em $30 \%$.

Nesse contexto, este trabalho objetivou avaliar o efeito da microbiolização de rizobactérias em sementes de cebola e a resposta sobre o desenvolvimento de plantas e a produção de bulbos.

\section{MATERIAL E MÉTODOS}

A pesquisa foi desenvolvida em Santa Catarina, na Estação Experimental da Epagri de Ituporanga (27 $25^{\circ}$ S, $49^{\circ} 38^{\prime} \mathrm{W}$ ), com altitude de $475 \mathrm{~m}$ acima do nível do mar e clima subtropical úmido (Cfa), segundo a classificação de Köeppen. O experimento foi conduzido a campo no período de julho a dezembro de 2007. Foram utilizadas sementes de cebola da cultivar 'Bola Precoce’ em razão do histórico de melhoramento e da utilização na região, além de estar entre as cultivares registradas de cebola indicadas para o cultivo em Santa Catarina. As sementes utilizadas apresentavam 86\% de germinação e 7,93\% de umidade.

Os isolados bacterianos utilizados no estudo fazem parte da coleção de RPCV do Dr. Wilmar Cório da Luz, obtidos da rizosfera de gramíneas da região de Passo Fundo, Rio Grande do Sul (RS). Vinte isolados foram microbiolizados em sementes de cebola e avaliados quanto aos parâmetros biométricos da parte aérea de mudas em condições de canteiros no ano 2006. Desses isolados, oito foram selecionados e fazem parte da pesquisa, juntamente com dois isolados previamente estudados e fornecidos pelo Dr. Reginaldo da Silva Romeiro da Universidade Federal de Viçosa (UFV), Minas Gerais (MG). Esses isolados foram previamente testados em tomate e feijão. Apresentaram resultados promissores quanto à promoção de crescimento das plantas (VIEIRA JUNIOR, 2005) e por isso foram também testados no experimento.

Os tratamentos de microbiolização nas sementes foram os seguintes: Pseudomonas spp. (W1), Pseudomonas spp. (W2), Pseudomonas spp. (W5), Pseudomonas spp. (W6), Bacillus megaterium (W7), Pseudomonas alcaligenes (W15), Paenibacillus polymyxa (W18), Bacillus megaterium (W19), Bacillus cereus (UFV040), Pseudomonas putida (UFV043) e testemunha sem microbiolização.

As rizobactérias foram multiplicadas em meio de cultura agar nutritivo (extrato de carne em pó para microbiologia $3 g$, peptona de carne $5 \mathrm{~g}$, glicose anidra 2,5g, agar $15 \mathrm{~g}$ e água destilada $1000 \mathrm{~mL}$ ), e as placas foram incubadas a $23 \pm 2^{\circ} \mathrm{C}$. Após 48 horas, as células foram removidas da superfície do meio de cultura com um pincel e colocadas em água destilada esterilizada. A concentração de cada rizobactéria foi de aproximadamente $10^{7} \mathrm{UFC} \mathrm{ml}^{-1}$, de acordo com a escala de McFarland (MCFARLAND, 1970). As sementes foram imersas nas suspensões bacterianas por cinco minutos, sendo agitadas, filtradas e deixadas para secar em temperatura ambiente, por 24 horas. As sementes da testemunha foram mantidas em água destilada esterilizada, agitadas por cinco minutos e deixadas secar à temperatura ambiente, por 24 horas.

A semeadura foi realizada a lanço, utilizandose $3 \mathrm{~g} \mathrm{~m}^{-2}$. As mudas foram produzidas em canteiros conforme metodologia descrita nas recomendações da Epagri/Sistema de Produção para cebola (EPAGRI, 2000). Durante a fase de produção de mudas, não foram efetuadas aplicações de agrotóxicos para controle de doenças.

As análises químicas, na camada de $0-20 \mathrm{~cm}$ do solo da área experimental de bulbos, resultaram em: $\mathrm{pH}\left(\mathrm{H}_{2} \mathrm{O}\right)=5,6 ; \mathrm{P}=11,0 \mathrm{mg} \mathrm{dm}^{-3} ; \mathrm{K}=328 \mathrm{mg} \mathrm{dm}^{-3}$; $\mathrm{Al}^{+3}=0,0 \mathrm{cmolc} \mathrm{dm}^{-3} ; \mathrm{Ca}^{+2}=7,0 \mathrm{cmolc} \mathrm{dm}^{-3} ; \mathrm{Mg}^{+2}=3$, $1 \mathrm{molc}$ $\mathrm{dm}^{-3}$; CTC $=17,1 \mathrm{cmolc} \mathrm{dm}^{-3} ; \mathrm{V} \%=64,0$, argila $=22 \%$ e matéria orgânica $=5,3 \%$. O transplante foi realizado 90 dias após a semeadura pelo método de cultivo mínimo sobre palhada de milheto. As mudas foram dispostas em quatro fileiras, no espaçamento de $0,1 \mathrm{~m}$ x 0,4m, em parcelas com $6,4 \mathrm{~m}^{2}$, em quatro repetições. A adubação de plantio constou da aplicação a lanço de $6 t \mathrm{ha}^{-1}$ de 
esterco de frango. Em cobertura, foram aplicados $210 \mathrm{~kg}$ ha $^{-1}$ de sulfamo (26\% N; 5\% Ca, 2\% Mg, 9\% S e 0,3\% B) aos 30 dias após o transplante. Durante a condução do experimento, foram efetuados os tratos culturais e fitossanitários recomendados para a cultura. Foram realizadas pulverizações com base em Lambdacyhalothrin, visando ao controle de tripes (Thripis tabaci) e pulverizações com os fungicidas Metalaxil-M + Clorotalonil (Folio Gold 375g $100 \mathrm{~L}^{-1}$ ) e Clorotalonil (Bravonil Ultrex 525g 100 $\mathrm{L}^{-1}$ ) alternadamente, utilizando-se um pulverizador com $\mathrm{CO}_{2}$ e bico do tipo DG 110015 ajustado para um volume de calda de 400L ha-2, totalizando cinco aplicações durante o ciclo da cultura. Realizaram-se ainda aplicações dos herbicidas (Ioxynil e Fenoxaprop-p-ethyl) em pósemergência a partir de 21 dias após o transplante (ANDREI, 1999). Os valores das precipitações e temperaturas médias mensais observadas durante o período de avaliação foram $233 \mathrm{~mm}$ e $11,1^{\circ} \mathrm{C}$ em julho; $113,9 \mathrm{~mm}$ e $13,5^{\circ} \mathrm{C}$ em agosto; $150,8 \mathrm{~mm}$ e $17,8^{\circ} \mathrm{C}$ em setembro; $216,5 \mathrm{~mm}$ e $19,1^{\circ} \mathrm{C}$ em outubro; $116,6 \mathrm{~mm}$ e $19,6^{\circ} \mathrm{C}$ em novembro.

A avaliação biométrica foi realizada aos 90 dias após o transplante (DAT). A altura da planta foi medida a partir do ponto de inserção das raízes até o ápice da maior folha com o auxílio de uma régua, o diâmetro do pseudocaule foi medido utilizando-se um paquímetro digital, o número de folhas foi contado, e a massa seca da parte aérea foi determinada. Para determinação da massa seca em balança analítica, as amostras foram acondicionadas em sacos de papel e levadas à estufa com circulação forçada de ar, regulada à temperatura de $60^{\circ} \mathrm{C}$, até o material atingir peso constante.

A contagem de plantas, para determinação da densidade de plantas por hectare, e a colheita dos bulbos foram realizadas 128 após o transplante, sendo a cura realizada ao sol durante duas semanas. A avaliação dos tratamentos foi realizada após a cura, e as características avaliadas foram o rendimento de bulbos ( $\mathrm{kg} \mathrm{ha}^{-1}$ ) e a massa fresca de bulbos (g), dividindo-se o rendimento de bulbos após a cura pelo número de plantas por hectare.

A classificação dos bulbos segundo o diâmetro transversal (cm) foi realizada de acordo com BRASIL (1995), que estabelece quatro classes, ou seja, Classe 2: maior que 35 e até $50 \mathrm{~mm}$ de diâmetro; Classe 3: maior que 50 e até $70 \mathrm{~mm}$; Classe 4 : maior que 70 e até $90 \mathrm{~mm}$ e Classe 5: maior que $90 \mathrm{~mm}$ e expressos em porcentagem.

Os dados foram testados quanto às pressuposições do modelo matemático e, em seguida, realizou-se a análise de variância, e as médias dos tratamentos foram comparadas pelo teste de Duncan, a $5 \%$ de probabilidade, segundo um delineamento em blocos casualizados, com quatro repetições. Os dados referentes às porcentagens foram transformados em $\mathrm{y}=\operatorname{arcsen}(\mathrm{x} / 100)^{1 / 2}$. Para a variável massa seca da parte aérea, os dados foram transformados em $y=1 / x$.

\section{RESULTADOS E DISCUSSÃO}

Os isolados pesquisados influenciaram os parâmetros biométricos avaliados aos 90DAT (Tabela 1). Quanto ao diâmetro de pseudocaule, ao número de folhas e à massa seca da parte aérea, verificou-se que houve diferenças significativas entre os tratamentos. Os isolados UFV40 e W5 foram os que mais influenciaram, diferindo da testemunha. A altura de plantas e o diâmetro de bulbos foram semelhantes entre os tratamentos, e apenas o isolado UFV40 apresentou diferença significativa em relação à testemunha.

A análise dos dados comprovou a efetividade do isolado UFV40 em promover o crescimento de plantas de cebola quando comparado à testemunha (Tabela 1). O tratamento com o isolado UFV40 apresentou maiores médias para todas as variáveis avaliadas aos 90DAT. O efeito benéfico do tratamento de sementes de cebola com isolados de rizobactérias observado por NEVES (2001) também foi verificado no presente trabalho, embora os resultados obtidos neste experimento tenham mostrado incrementos menores. Entretanto, houve respostas significativas na mesma fase de desenvolvimento das plantas, ou seja, no período de bulbificação. Segundo CARDOSO \& NOGUEIRA (2007), conforme a planta se desenvolve e atinge maior atividade fisiológica, com aumento do sistema radicular e da parte aérea, maiores quantidades e diversidade de produtos são liberadas para a rizosfera, aumentando a atividade dos microrganismos, inclusive os promotores de crescimento vegetal.

Os isolados W6, W19 e UFV40 apresentaram aumentos significativos de $48 \%$, 46\% e $45 \%$, respectivamente, no rendimento de bulbos por hectare em relação à testemunha (Tabela 2), embora não tenham diferido estatisticamente dos tratamentos W1, W2, W5, W7 e W15. Os demais tratamentos não apresentaram aumentos significativos para a variável rendimento de bulbos.

Os tratamentos apresentaram população entre 235.417 e 272.917 plantas por hectare (Tabela 2). O tratamento W19 teve o maior número de plantas no final do ciclo, e o W7 teve o menor número. Interagindo com a planta, rizobactérias podem ter efeito deletério, nulo ou benéfico. Algumas rizobactérias afetam 
Tabela 1 - Efeito do tratamento de sementes de cebola com rizobactérias sobre os parâmetros biométricos: diâmetro do pseudocaule (DP), número de folhas (NF), massa seca da parte aérea (MSPA), altura (A) e diâmetro de bulbos (DB) avaliados aos 90 dias após o transplante de mudas. Cultivar 'Bola Precoce'. Ituporanga, SC, 2007.

\begin{tabular}{|c|c|c|c|c|c|}
\hline \multirow{3}{*}{$\begin{array}{l}\text { Tratamentos } \\
\text { Pseudomonas spp. W1 }\end{array}$} & \multirow[t]{2}{*}{$\begin{array}{l}\mathrm{DP} \\
\mathrm{mm}\end{array}$} & \multirow[t]{2}{*}{ NF } & \multirow{2}{*}{$\begin{array}{c}\text { MSPA } \\
\text { g }\end{array}$} & \multirow{2}{*}{$\begin{array}{l}\mathrm{A} \\
\mathrm{cm}\end{array}$} & \multirow[t]{2}{*}{$\begin{array}{l}\mathrm{DB} \\
\mathrm{mm}\end{array}$} \\
\hline & & & & & \\
\hline & $14,2 \mathrm{abc}^{1}$ & 8,0 abc & $7,800 \quad a b$ & $62,9 \quad a b$ & $30,6 \quad a b$ \\
\hline Pseudomonas spp. W2 & 13,7 abc & 7,8 abc & $5,075 \mathrm{ab}$ & 59,9 ab & $26,9 \mathrm{ab}$ \\
\hline Pseudomonas spp. W5 & $15,0 \quad a b$ & $8,3 \mathrm{ab}$ & 7,450 a & 63,6 ab & 30,9 ab \\
\hline Pseudomonas spp. W6 & 14,3 abc & 7,9 abc & $5,650 \quad a b$ & 64,3 ab & $25,8 \quad a b$ \\
\hline Bacillus megaterium W7 & 14,1 abc & 8,1 abc & 7,000 ab & 61,8 ab & 29,6 ab \\
\hline Pseudomonas alcaligenes W15 & 12,9 bc & 7,9 abc & $5,300 \quad a b$ & 57,3 b & $27,7 \quad a b$ \\
\hline Paenibacillus polymyxa W18 & 13,4 abc & 7,4 bc & 4,725 ab & 57,7 b & 25,6 \\
\hline Bacillus megaterium W19 & 13,9 abc & 8,1 abc & 5,125 ab & 59,3 ab & 25,8 \\
\hline Bacillus cereus UFV40 & 15,7 a & 8,8 a & 8,125 a & 66,4 a & 32,0 \\
\hline Pseudomonas putida UFV43 & 14,3 abc & 8,1 abc & $5,650 \mathrm{ab}$ & $59,3 \mathrm{ab}$ & 26,1 \\
\hline Testemunha & 12,4 c & 7,2 c & $4,225 \mathrm{~b}$ & 56,3 b & $23,7 \quad b$ \\
\hline Médias & 14,0 & 7,9 & 6,011 & 60,8 & 27,7 \\
\hline Desvio padrão & 0,9 & 0,4 & 1,341 & 3,3 & 2,6 \\
\hline CV (\%) & 9,91 & 7,76 & 26,6 & 8,32 & 15,9 \\
\hline
\end{tabular}

${ }^{1}$ Médias seguidas da mesma letra na coluna não diferem significativamente entre si pelo teste de Duncan $(\mathrm{P}=0,05)$.

negativamente as plantas com ação deletéria, reduzindo o número de plantas por hectare (PELTZER et al., 2004). Esse fato pode explicar essas diferenças entre tratamentos. Houve efeito dos tratamentos para o parâmetro peso médio de bulbo (Tabela 2). Os isolados W6, UFV40, W1 apresentaram maior peso médio de bulbos, com diferença significativa para os valores da testemunha e para o isolado UFV43.
O fato de isolados de outras regiões e obtidos de outras espécies vegetais terem promovido crescimento em plantas de cebola sugere a não especificidade, como relatada por QUADTHALLMANN \& KLOEPPER (1996), segundo os quais isolados originados de um hospedeiro podem colonizar outros hospedeiros de espécies diferentes, até mesmo com maior intensidade.

Tabela 2 - Efeito do tratamento de sementes de cebola com rizobactérias sobre o rendimento de bulbos por hectare (R), a população de plantas por hectare (P) e o peso médio de bulbo (PMB) avaliados aos 128 dias após o transplante. Cultivar 'Bola Precoce'. Ituporanga, SC, 2007.

\begin{tabular}{|c|c|c|c|c|}
\hline Tratamentos & $\mathrm{R}$ (kg/ha) & Diferença ${ }^{1} \%$ & $\mathrm{P}\left(\mathrm{n} \mathrm{ha}^{-1}\right)$ & PMB (g) \\
\hline Pseudomonas spp. W1 & $21.927 \mathrm{abc}^{2}$ & 38 & 250.000 ab & 87,7 a \\
\hline Pseudomonas spp. W2 & 20.417 abc & 29 & $266.667 \mathrm{ab}$ & 76,2 abc \\
\hline Pseudomonas spp. W5 & 21.521 abc & 36 & $266.667 \mathrm{ab}$ & 80,8 abc \\
\hline Pseudomonas spp. W6 & 23.375 a & 48 & 264.583 ab & 88,3 a \\
\hline Bacillus megaterium W7 & $17.863 \mathrm{abc}$ & 13 & 235.417 b & 75,7 abc \\
\hline Pseudomonas alcaligenes W15 & 17.994 abc & 14 & 260.417 ab & 69,2 abc \\
\hline Paenibacillus polymyxa W18 & 16.815 bc & 6 & $258.333 \mathrm{ab}$ & 65,3 abc \\
\hline Bacillus megaterium W19 & 23.104 a & 46 & 272.917 a & 85,9 ab \\
\hline Bacillus cereus UFV40 & $23.000 \mathrm{ab}$ & 45 & $258.333 \mathrm{ab}$ & 88,6 a \\
\hline Pseudomonas putida UFV43 & 16.302 с & 3 & $266.667 \mathrm{ab}$ & 61,7 \\
\hline Testemunha & $15.844 \mathrm{c}$ & 0 & $245.833 \mathrm{ab}$ & 63,9 bc \\
\hline Médias & 19.833 & & 258.712 & 76,6 \\
\hline Desvio padrão & 2.926 & & 11.016 & 10,3 \\
\hline CV (\%) & 18,9 & & 7,79 & 18,43 \\
\hline
\end{tabular}

${ }^{1}$ Diferença no rendimento de bulbos em relação à testemunha, expressa em porcentagem.

${ }^{2}$ Médias seguidas da mesma letra na coluna não diferem significativamente entre si pelo teste de Duncan $(\mathrm{P}=0,05)$. 
Dentre os tratamentos, o isolado UFV40 apresentou maior porcentagem de bulbos na classe 3 (69,6\%), considerada como a ideal para comercialização (Tabela 3). Os tratamentos com os isolados W1, W5, W19 e UFV40 não apresentaram refugo. Os tratamentos W15, W18 e a testemunha apresentaram porcentagem de bulbos na classe 3 abaixo de $40 \%$, além de elevada porcentagem de bulbos na classe 2 (acima de 50\%), também considerada como padrão inferior de acordo com a classificação do Ministério da Agricultura Pecuária e Abastecimento (BRASIL, 1995). O isolado UFV40 exerceu efeito positivo sobre a produção de biomassa da parte aérea, o que pode ter refletido no aumento no tamanho de bulbos e na melhor classificação destes, como resultado do melhor desenvolvimento da planta propiciado pela microbiolização do isolado mais eficiente. Esses resultados confirmam o pontencial do isolado UFV40 na promoção de crescimento de plantas obtido por VIEIRA JUNIOR (2005) com a cultura do feijoeiro.

A maioria dos trabalhos com RPCV utiliza um grande número de isolados nas seleções preliminares (CHEN et al., 1996). No entanto, apesar do número reduzido de isolados testados neste trabalho, alguns deles promoveram o crescimento de plantas e a produção de bulbos de cebola. Por outro lado, não se conhece a capacidade e o tipo de colonização dessas bactérias nas sementes e raízes de cebola, uma vez que não foram feitos ensaios específicos para quantificar a população bacteriana na superfície e no interior dos órgãos.
Sabe-se, no entanto, que os isolados pertencem aos gêneros Bacillus e Pseudomonas, que são residentes comuns do filoplano de plantas cultivadas, além de serem isolados da rizosfera de várias espécies vegetais (KLOEPPER et al., 2004; SHAHAROONAet al., 2008). Além disso, LODEWYCKX et al. (2002) incluem esses gêneros entre os endofíticos comuns em várias espécies vegetais. Os isolados podem ter colonizado, tanto externa, como internamente as mudas de cebola, já que essas bactérias apresentam a capacidade de colonizar os tecidos da planta, podendo sintetizar hormônios de crescimento ou induzir a síntese desses compostos, como auxinas, citocininas e giberelina, que influenciam o crescimento das plantas (COCKING, 2003).

\section{CONCLUSÕES}

O tratamento de sementes de cebola com rizobactérias influencia o desenvolvimento da cultura, e os isolados que promovem melhor rendimento de bulbos são Pseudomonas spp. W6 e Bacillus cereus UFV40, os quais apresentam potencial para multiplicação e uso como bioinoculantes que podem ser utilizados na produção de cebola.

\section{AGRADECIMENTOS}

Os autores agradecem à Coordenação de Aperfeiçoamento de Pessoal de Nível Superior (CAPES), pela

Tabela 3 - Efeito do tratamento de sementes de cebola com rizobactérias sobre a classificação comercial de bulbos. Cultivar 'Bola Precoce'. Ituporanga, SC, 2007.

\begin{tabular}{|c|c|c|c|c|}
\hline & Classe 4 & Classe 3 & Classe 2 & Refugo \\
\hline Pseudomonas spp. W1 & $2,5^{\mathrm{ns}}$ & $56,6 \mathrm{ab}^{1}$ & $39,2 \quad a b$ & $0^{\mathrm{ns}}$ \\
\hline Pseudomonas spp. W2 & 0 & 51,4 ab & $44,4 \mathrm{ab}$ & 2,7 \\
\hline Pseudomonas spp. W5 & 0,7 & 51,1 ab & $48,2 \mathrm{ab}$ & 0 \\
\hline Pseudomonas spp. W6 & 1,6 & $64,5 \mathrm{ab}$ & $29,9 \quad b$ & 1,6 \\
\hline Bacillus megaterium W7 & 0,8 & $49,4 \quad a b$ & $44,4 \mathrm{ab}$ & 3,5 \\
\hline Pseudomonas alcaligenes W15 & 0 & $36,1 \quad b$ & 60,0 a & 3,1 \\
\hline Paenibacillus polymyxa W18 & 0 & $35,7 \quad b$ & 59,3 a & 1,7 \\
\hline Bacillus megaterium W19 & 1,6 & $59,1 \mathrm{ab}$ & $38,5 \mathrm{ab}$ & 0 \\
\hline Bacillus cereus UFV40 & 0,8 & 69,6 а & 28,1 b & 0 \\
\hline Pseudomonas putida UFV43 & 0 & $46,2 \mathrm{ab}$ & $42,3 \mathrm{ab}$ & 4,6 \\
\hline Testemunha & 1,6 & 34,1 b & 57,5 a & 4,4 \\
\hline Médias & 0,9 & 50,3 & 44,7 & 1,9 \\
\hline Desvio padrão & 0,8 & 11,7 & 10,9 & 1,8 \\
\hline CV\% & 191,80 & 25,00 & 24,01 & 131,31 \\
\hline
\end{tabular}

${ }^{\text {ns }}$ Efeito de tratamento não significativo.

${ }^{1}$ Médias seguidas da mesma letra na coluna não diferem significativamente entre si pelo teste de Duncan $(\mathrm{P}=0,05)$.

Ciência Rural, v.39, n.9, dez, 2009. 
concessão de Bolsa de Doutorado; ao Laboratório da Embrapa Meio Ambiente, pela identificação das rizobactérias; e ao Dr. Reginaldo da Silva Romeiro, da Universidade Federal de Viçosa, pela cessão dos isolados UFV40 e UFV43.

\section{REFERÊNCIAS}

ANDREI, E. Compêndio de defensivos agrícolas. 6.ed. São Paulo: Andrei, 1999. 676p.

BADAWY, F.H. et al. Effect of inoculations with single and mixed bacterial strains on field grown onion. Assiut Journal of Agricultural Sciences, v.34, p.301-312, 2003.

BASHAN, Y.; BASHAN, L.E. Bacteria - Plant growthpromoting. In: HILLEL, D. Encyclopedia of soils in the environment. Oxford: Elsevier, 2005. V.1, p.103-115.

BRASIL. Ministério da Agricultura, Abastecimento e Reforma Agrária. Portaria n.529 de 18 ago. 1995. Diário Oficial da República Federativa do Brasil, Brasília, 1 set.1995, Seção 1 , p.13513.

CARDOSO, E.J.B.N.; NOGUEIRA, M.A. A rizosfera e seus efeitos na comunidade microbiana e na nutrição de plantas. In: SILVEIRA, A.P.D.; FREITAS, S.S. (Eds.). Microbiota do solo e qualidade ambiental. Campinas, SP: Instituto Agronômico, 2007. p.79-96.

CASTRO, V.L.S.S.; MELO, I.S. Avaliação toxicopatológica em ratos expostos à Pseudomonas putida. Journal Brazilian Society Ecotoxicology, v.2, p.1-5, 2007.

CHEN, Y. et al. The use of yield increasing bacteria (YIB) as plant growth-promoting rhizobacteria in chinese agriculture. In: UTKHEDE, R.S.; GUPTA, V.K. (Eds.). Management of soil born diseases. Ludhiana: Kalyani Publishers, 1996. p.165184.

COCKING, C.E. Endophytic colonization of plant roots by nitrogen-fixing bacteria. Plant and Soil, v.252, p.169-175, 2003.

EPAGRI. Sistema de produção para cebola: Santa Catarina 3.rev. Florianópolis: 2000. 91p. (Epagri. Sistemas de Produção, 16).

FREITAS, S.S.; AGUILAR VILDOSO, C.I. Rizobactérias e promoção do crescimento de plantas cítricas. Revista Brasileira de Ciência do Solo, v.28, p.987-994, 2004. Disponível em: $<$ http://www.scielo.br/scielo.php?script=sci_arttext\&pid=S010006832004000600007\&lng=en>. Acesso em: 15 jul. 2008. doi: 10.1590/S0100-06832004000600007.
KLOEPPER, J.W. et al. Induced systemic resistance and promotion o plant growth by Bacillus spp. Phytopathology, v.94, p.1259-1266, 2004.

LODEWYCKX, C. et al. Endophytic bacteria and their potential applications. Critical Reviews in Plant Sciences, v.21, p.583-606, 2002.

LUZ, W.C. Rizobactérias promotoras de crescimento de plantas e de bioproteção. In: LUZ, W.C. et al. (Ed.). Revisão anual de patologia de plantas. Passo Fundo: RAPP, 1996. p.1-49.

MCFARLAND, J. The nephelometer: an instrument for estimating the number of bacteria in suspensions used for calculating the opsonic index and for vaccines. In: CAMPBELL, H.D. et al. (Eds.). Methods in immunology. New York: Benjamin, 1970. p.435-437.

NEVES, D.M.S. Controle biológico de Pseudomonas marginalis Pv. Marginalis e promoção de crescimento de cebola pela microbiolização de sementes. 2001. $47 \mathrm{f}$. Dissertação (Mestrado em Fitopatologia) - Faculdade de Agronomia Eliseu Maciel, Universidade Federal de Pelotas, RS.

PELTZER, S.C. et al. Deleterious rhizobacteria for biological control of annual cropping weeds in Australia and South Korea. Weed Science Society of America Meeting Abstracts, n.79, 2004. CD.

QUADT-HALLMANN, A.; KLOPPER, J.W. Immunological detection and localization of the cotton endophyte Enterobacter asburiae JM22 in different plant species. Canadian Journal of Microbiology, v.42, p.1144-1154, 1996.

RAMAMOORTHY, V. et al. Induction of systemic resistance by plant growth promoting rhizobacteria in crop plants against pests and diseases. Crop Protection, v.20, p.1-20, 2001.

SHAHAROONA, B. et al. Fertilizer-dependent efficiency of Pseudomonads for improving growth, yield, and nutrient use efficiency of wheat (Triticum aestivum L.). Applied Microbiology and Biotechnology, v.79, p.147-155, 2008.

TARNAWSKI, S. et al. Phenotypic structure of Pseudomonas populations is altered under elevated pCO in the rhizosphere of perennial grasses. Soil Biology \& Bî̉ochemistry, v.38, p.1193-1201, 2006.

VIEIRA JUNIOR, J.R. Procariotas residentes de filoplano do feijoeiro como agentes de biocontrole de enfermidades da parte aérea da cultura. 2005. $146 \mathrm{f}$. Tese (Doutorado em Fitopatologia) - Departamento de Fitopatologia, Universidade Federal de Viçosa, MG. 